\title{
A NARRATIVA COMO OPÇÃO METODOLÓGICA NA FORMAÇÃO DOS/AS PROFESSORES/AS DE CIÊNCIAS E BIOLOGIA PARA A TRATATIVA DO CONTEÚDO “CORPO HUMANO"*
}

\author{
Nilda Masciel Neiva \\ Elenita Pinheiro de Queiroz Silva
}

\section{Introdução}

A proposta metodológica que aqui apresentamos é resultado de uma pesquisa-formativa realizada pela pesquisadora Nilda Masciel Neiva durante o seu doutorado na Universidade Federal de Uberlândia e sob a orientação da professora Doutora Elenita Pinheiro de Queiroz Silva, também coordenadora do Grupo de Pesquisa Corpo, Gênero e Sexualidade (GEPCS). Cabe aqui ressaltar que as discussões sobre "corpo", realizadas no grupo de pesquisa GEPCS, foram de fundamental importância para o planejamento, execução e análise das fontes da pesquisa, pois à medida que fomos enveredando pelas discussões sobre a história do corpo, a sua abordagem sociológica, filosófica, antropológica e educacional, fomos sendo tomadas por um profundo desconforto com o olhar que projetamos sobre o trabalho docente durante o estágio curricular supervisionado centrado na perspectiva de corpo fragmentado, disciplinado, acultural. Passamos a observar que este trabalho se desencadeia inclusive na nossa trajetória pessoal, pelo fato de que o corpo humano, apresentado na escola e em cursos de formação docente, é atrelado à perspectiva da biomedicina, sem articulação com a perspectiva sociocultural. Então, as experiências pessoais de aprofundamento teórico no grupo de pesquisa possibilitaram pensar o conhecimento biológico e seu ensino em articulação com campos sociais e culturais.

Esboçar a proposta da pesquisa-formação se tornou um desafio por compreendermos ser essencial para a articulação entre Biologia e cultura, por exemplo, pensar a produção de modos de ensinar e de experimentar o corpo com os/as estagiários/as, buscando a ruptura e superação da raciona-

"DOI - 10.29388/978-65-86678-66-6-f.175-192 
lidade técnica, da fragmentação e do deslocamento da cultura. Emergiu, assim, possibilidades de formação para nós, formadoras, enquanto professoras-pesquisadoras e para os/as estagiários/as, por meio da proposição e criação de vínculos e de parcerias no processo de experienciarmos a produção de modos de pensar e ensinar o tema corpo humano, com a perspectiva do estabelecimento da articulação de conhecimentos biológicos e culturais.

Nesse sentido, apresentamos nesse capítulo uma opção metodológica utilizada no estágio curricular supervisionado, no contexto do curso de Ciências Biológicas, para a (des)construção de conhecimentos sobre o corpo, onde diversas formas narrativas repletas de significado nortearam reflexões ao longo do processo formativo proposto no componente curricular Estágio Supervisionado. Desse modo, o trabalho fundamentou-se metodologicamente nas produções de Josso (2002), Souza (2006), Galvão (2005), Abrahão (2004), dentre outros estudiosos.

\section{O movimento para a produção das narrativas de corpo}

Ao buscarmos a narrativa como oportunidade de pesquisa emergimos na ideia do/a estagiário/a como um/a narrador/a criativo/a na singularidade da situação de narração, pois "a escrita da narrativa remete o sujeito para uma dimensão de autoescuta de si mesmo, como se tivesse contando para si próprio suas experiências e as aprendizagens que construiu ao longo da vida, através do conhecimento de si" (SOUZA, 2006, p. 47) ${ }^{1}$. Nessa perspectiva, a narrativa permite uma interrogação das representações do saberfazer e dos referenciais que servem para descrever e compreender-se a si próprio, no seu ambiente humano e natural (SOUZA, 2006). Os registros permitem, assim, observar a formação e dizer até que ponto ela se constitui como experiência formadora.

Desse modo, o aporte nas produções narrativas imagéticas, orais e textuais e sua sistematização como projeto de aprendizagens experienciais, e, ao mesmo tempo, como procedimento de pesquisa, em contexto de in-

\footnotetext{
${ }^{1}$ Obra de Elizeu Clementino de Souza que procura enfocar o sentido e a fertilidade da construção da narrativa de formação e suas relações com os espaços, tempos, rituais e aprendizagens da prática docente no âmbito do estágio supervisionado.
} 
vestigação-formação, justifica-se por acreditarmos nas possibilidades e potencialidades da narrativa como suporte reflexivo para compreensão do conhecimento biológico enquanto conhecimento cultural no contexto da formação de professores/as de Biologia. O pressuposto é o de que o conhecimento de si contribui para a produção do processo de formação docente.

Partimos da proposição de que ao corpo dos/as estagiários/as em formação são artefatos, hábitos, crenças, normas morais, tabus, preconceitos, prazeres, expertises agregados, experiências vividas que contribuem na construção de subjetividades próprias de uma pessoa ou grupos de pessoas. Dessa forma, quando buscamos a narrativa do corpo do/a estagiário/a em formação durante o Estágio Supervisionado, desejamos enfatizar aspectos individuais e subjetivos da experiência vivida durante a interformação para o entendimento de uma noção de corpo que não se constitui apenas de partes isoladas, independentes, mas também como produtor de histórias e espaço de transformação; é biológico e também cultural, social e político.

Entender a dinâmica de produção do corpo a partir do olhar do estagiário/a sobre o seu próprio corpo, no espaço onde estão em processo de formação, foi uma escolha que nos oportunizou a aproximação aos sujeitos (alunos/as) de forma espontânea, precisa e dinâmica, ao tempo que possibilitou a análise numa perspectiva interpretativa-compreensiva ${ }^{2}$.

Nessa linha, buscamos com a produção individual e coletiva de narrativas dos/as estagiários/as pela possibilidade formativa de desnaturalização de concepções de corpo instituídas nos/pelos programas oficiais de ensino a partir de um processo histórico de naturalização de verdades únicas e universais, como a verdade do corpo biomédico. Refletir sobre a construção historicamente naturalizada sobre o corpo a partir da modernidade e, ainda, sobre como trabalhar com estas construções, bastante arraigadas na escola e na sociedade, também constituiu um grande desafio para nós.

A escuta sensível dos partícipes da pesquisa foi realizada como dispositivo significativo para fazer a investigação-formação com narrativas e também como forma humanizante ${ }^{3}$ e educativa, já que a narrativa como

\footnotetext{
${ }^{2}$ A perspectiva interpretativa-compreensiva a qual faço referência relaciona-se a produção do corpo do próprio estagiário/a no espaço de formação inicial e as relações que permeiam nesse espaço a constituição dos corpos.

${ }^{3}$ Humanizante e educativa contrapondo-se a forma que somos empurrados para explicar, compulsivamente, em face de uma formação pautada no significado autoritário (BRUNER, 2001) e na razão descontextualizada (MACEDO, 2000).
} 
"ação comunicativa" é um dos subsídios insubstituíveis neste tipo de investigação, nos afirma Macedo (2000.).

Neste trabalho, tomamos as narrativas como possibilidades de autoconhecimento e apresentação de experiências que deixaram marcas e que produzem o corpo, podendo apresentar os diversos fios que compõem o mesmo. A escolha da pesquisa com narrativas ocorreu, para além dos argumentos já assinalados anteriormente, por compreender a oportunidade do trabalho com histórias plenas de significados, em que os participantes se desvelam para si, e se revelam para os demais. Por excelência, as narrativas - sejam individuais ou coletivas - são constituídas por histórias que possibilitam a (auto) compreensão, o conhecimento de si, para aquele que narra (SOUSA, 2006).

Dessa forma, cabe ressaltar que não buscamos, com a narrativa, estabelecer generalizações estatísticas, mas compreender o corpo e a articulação conhecimento biológico e cultura. Comungando com Moita (1995), consideramos a pesquisa narrativa com potencial de diálogo entre o individual e o sociocultural e, de modo similar a Ferrarotti (1988), acreditamos que nos estudos narrativos imbricam-se o eu pessoal e o eu social; o indivíduo e o coletivo.

Tomamos a narrativa também como "o estudo das diferentes maneiras como os seres humanos experimentam o mundo" (GALVÃO, 2005, p. 328), cabendo nesta frisar a perspectiva tridimensional do tempo. A noção de tempo, então, é uma noção fundamental para quem faz uso da narrativa. Os sujeitos que narram, o fazem no movimento de articulação entre presente-passado-futuro. Assim, a consideração do tempo é algo a ser pensado pelo/a pesquisador/a que toma as narrativas como possibilidade investigativa. Para a compreensão de tal noção e movimento, fizemos uso de Abrahão (2002), para quem a narrativa se "apresenta no tempo pensado/vivenciado, com as ambiguidades e, mesmo, contradições no seio dessas três instâncias: passado, presente, futuro" (p. 207).

Desse modo, "[...] a realidade cotidiana é percebida por cada um de nós de um modo muito particular, damos sentido às situações por meio do nosso universo de crenças, elaborado a partir das vivências, valores e papéis culturais inerentes ao grupo social a que pertencemos" (GALVÃO, 2005, p. 328). 
Assim, as narrativas permitem construir um percurso individual/coletivo com histórias que ouvimos ou vivemos, e a realidade cotidiana é percebida de forma muito particular por cada um dos sujeitos, "[...] dando diferentes status de realidade a experiências que criamos a partir de diferentes encontros com o mundo" (GALVÃO, 2005, p. 328). Para Benjamim (1996), as narrativas, ao articularem presente, passado e futuro, quebram o modo linear de significar trajetórias e vivências no espaço-tempo, são instigadas pela rememoração, trazendo uma vida lembrada por quem a viveu.

Na narrativa, as palavras têm significado e não é somente raciocinar, calcular ou argumentar, mas, sobretudo, dar sentido ao que somos e ao que nos acontece, "[...] portanto, também tem a ver com as palavras, o modo como nos colocamos diante de nós mesmos, diante dos outros e diante do mundo em que vivemos" (LARROSA, 1994, p. 21). Nas narrativas, o uso das palavras torna-se essencial para desvelar o que somos e o que nos acontece; o que é e o que acontece ao corpo.

Assim, as histórias podem ser um terreno para análise, se não ignoramos todos os aspectos por elas apresentados. Têm como mérito o fato de poderem ser contextualizadas, analisadas por diferentes perspectivas, à medida que podem ser contadas e discutidas em grupos de formação (GALVÃO, 2005).

Tendo como suporte as ideias de Galvão, a pesquisa que propomos teve a narrativa como método de investigação ${ }^{4}$. Compreendemos que se trata de um processo moroso, que exige muita dedicação por parte do/a investigador/a. De forma cuidadosa, os dados foram produzidos junto aos/as estagiários/as e, simultaneamente, interpretados com os sujeitos que viveram a experiência.

Ao trabalhar com narrativas, é preciso ainda que reconheçamos e aceitemos o processo de reconstrutividade da memória e a dinâmica de ressignificação, dos quais narradores/as fazem uso ao longo das trajetórias de narração.

\footnotetext{
4 “A narrativa como método de investigação pressupõe uma postura metodológica firmada na interação entre investigador e participantes, um jogo de relações baseado na confiança mútua e na aceitação da importância da intervenção de cada um na coleta dos dados e na sua interpretação". (GALVÃO, 2005, p. 342).
} 
O conhecimento narrativo está baseado em uma epistemologia construtivista e interpretativa. A linguagem media a experiência e a ação. A narrativa é uma estrutura central no modo como os humanos constroem o sentido. $O$ curso da vida e a identidade pessoal são vividos como uma narração. A trama argumentativa configura o relato narrativo.

Temporalidade e narração formam um todo: o tempo é constituinte do significado. As narrativas individuais e as culturais estão inter-relacionadas (BOLÍVAR, 2001, p. 220).

Destacamos na citação de Bolívar (2001) que o tempo e a narração estão interconectados. Tal interconexão foi observada à medida que os sujeitos da pesquisa foram narrando seus corpos, o que nos permitiu - mediadas pela base teórica sobre corpo que construímos - ver desvelados elementos do processo histórico, relações subjetivas e culturais nas quais o grupo estava imerso.

Nesse contexto, a narrativa tomada como produção do corpo dos/ as estagiários/as, se liga e se define ao próprio objeto de estudo e aos desafios colocados na presente pesquisa, sendo a experiência considerada, ao mesmo tempo, pessoal e social; individual e coletiva. Um critério da experiência é a continuidade, ou seja, uma experiência leva a outras experiências, e os indivíduos se posicionam nesse continuum ${ }^{5}$. Portanto, "aprendemos a nos mover para trás (retrospectivamente) e para frente (prospectivamente) entre o pessoal e o social, simultaneamente pensando sobre o passado, o presente e o futuro, e assim agir em todos os millieus sociais em expansão". (CLANDININ; CONNELLY, 2015, p.31).

Com essas questões em mente, a continuidade tornou-se uma busca dessas investigadoras pela construção de narrativas que abririam possibilidades metodológicas para produção das fontes elaboradas em situação de interformação, considerando os sujeitos como portadores/as e construtores/as de saberes a partir de suas experiências.

$\mathrm{Na}$ perspectiva da acepção das individualidades, tomamos a subjetividade e o valor heurístico, conforme Ferraroti (1988, p.57), “[...] como axiomas fundamentais para os limites de cientificidade e de oposição a exigências de representatividade objetiva e nomotética das narrativas".

\footnotetext{
${ }^{5}$ Onde quer que alguém se posicione nesse continuun - o imaginado agora, algo imaginado no passado, ou um imaginado futuro - cada ponto tem uma experiência passada como base e cada ponto leva a uma experiência futura. (CLANDININ; CONNELLY, 2015, p.30)
} 
Aliada a essa ideia, apropriamo-nos ainda da noção de pesquisa narrativa, como a elaborada por Josso (2010):

A pesquisa narrativa na situação de intersubjetividade permite, assim, uma escuta além disso, uma exploração das emergências interiores (sob a forma de desejos, anseios, projetos) que revelam uma busca ativa de realização do ser humano em suas potencialidades insuspeitas ou inesperadas. Essas descobertas pressupõem uma visão do humano (um dos sustentáculos de nossa cosmogonia) que autoriza a imaginar e a acreditar na possibilidade de poder, querer e ter que desenvolver ou adquirir o saber-fazer, saber-sentir, saber-pensar, saberescutar, saber nomear, saber imaginar, saber-avaliar, saber-perseverar, saber-amar, saber-projetar, saber-desejar, saber-estar em relação com um eu-encarnado etc., que são necessários às mudanças, à acolhida do desconhecido que vem ao nosso encontro assim que deixamos o caminho de vida programado por nossas histórias familiar, sociais e cultural. (JOSSO, 2010, 173-174)

Nesse sentido, como pesquisadoras, aprendemos que os/as participantes não são termos, categorias, teorias isoladas, são pessoas com todas as suas complexidades: "são pessoas vivendo vidas historiadas em paisagens historiadas." (CLANDININ; CONNELLY, 2015, p.193). Ao apresentarmos a metodologia que utilizamos para a tratativa do tema "corpo humano", em seguida consideramos essa aprendizagem.

\section{Uma metodologia para a tratativa do tema "corpo humano" em cursos de formação de professores}

O movimento inicialmente realizado pelas pesquisadoras junto aos estagiários/as foi o seguinte: 1- apresentação e levantamento do interesse pela pesquisa, que tem a aprovação do CEP, conforme parecer de № 3 . 342.226; 2- Esclarecimentos recomendados pelo Comitê de Ética aos/as participantes, e verificado as pessoas que demonstraram desejo de participar da pesquisa, foi apresentado o convite para que os/as mesmos/as inici- 
assem a produção das narrativas do corpo pelo grupo de estagiários/as em formação. Com o diálogo, questões éticas foram acordadas, como a manutenção do anonimato dos participantes, horário e local de realização dos encontros e a necessidade da escuta atenta das narrativas produzidas. Em respeito aos princípios éticos da pesquisa com seres humanos, os Termos de Consentimento Livre e Esclarecido foram assinados, e para manutenção do anonimato dos participantes, reportamo-nos a estes como E01, E02, E03, [...], E25, nesse trabalho.

O estudo que realizamos contou com 25 participantes, e o diálogo perdurou ao longo de toda a produção das narrativas, a saber: desenho do corpo do estagiário, produzido individualmente e coletivamente; narrativa escrita e oral dos corpos dos estagiários, também produzidos individualmente e coletivamente; produção de histórias com os corpos construídos em grupos narrativos; estudo de textos que versam sobre a constituição do corpo na escola e currículo; produção de mural a partir dos desenhos de corpos produzidos.

O momento da produção das narrativas foi determinante para o alcance dos objetivos da pesquisa. Assim, os participantes foram notificados/as que estaria instalada uma câmera para a filmagem do momento da produção das narrativas, com a finalidade exclusiva de rememoração do encontro pelas pesquisadoras com auxílio das imagens que permitem a observação dos comportamentos, movimento, falas, entre outros aspectos. Esse, porém, não foi um obstáculo, pois não houve objeções quanto à presença da câmera entre nós. Em comum acordo, os momentos de encontro foram firmados duas vezes por semana, com duração de duas horas e trinta minutos cada um, compondo um total de 08 encontros, que ocorreram no período de 03 a 27 de junho de 2019. Na figura a seguir estão expostas as ações formativas da produção das narrativas ${ }^{6}$ sobre corpo e a mobilização de saberes na articulação conhecimento biológico e cultura.

\footnotetext{
${ }^{6}$ Cabe informar que esta proposta está inspirada em um trabalho de extensão, realizado em uma escola pública da rede municipal da cidade de Uberlândia, coordenada pela orientadora deste trabalho e desenvolvido no âmbito das atividades de pesquisa do GPECS/PPGED/UFU, no ano de 2015.
} 
Figura 1- Ações formativas da produção do corpus da pesquisa

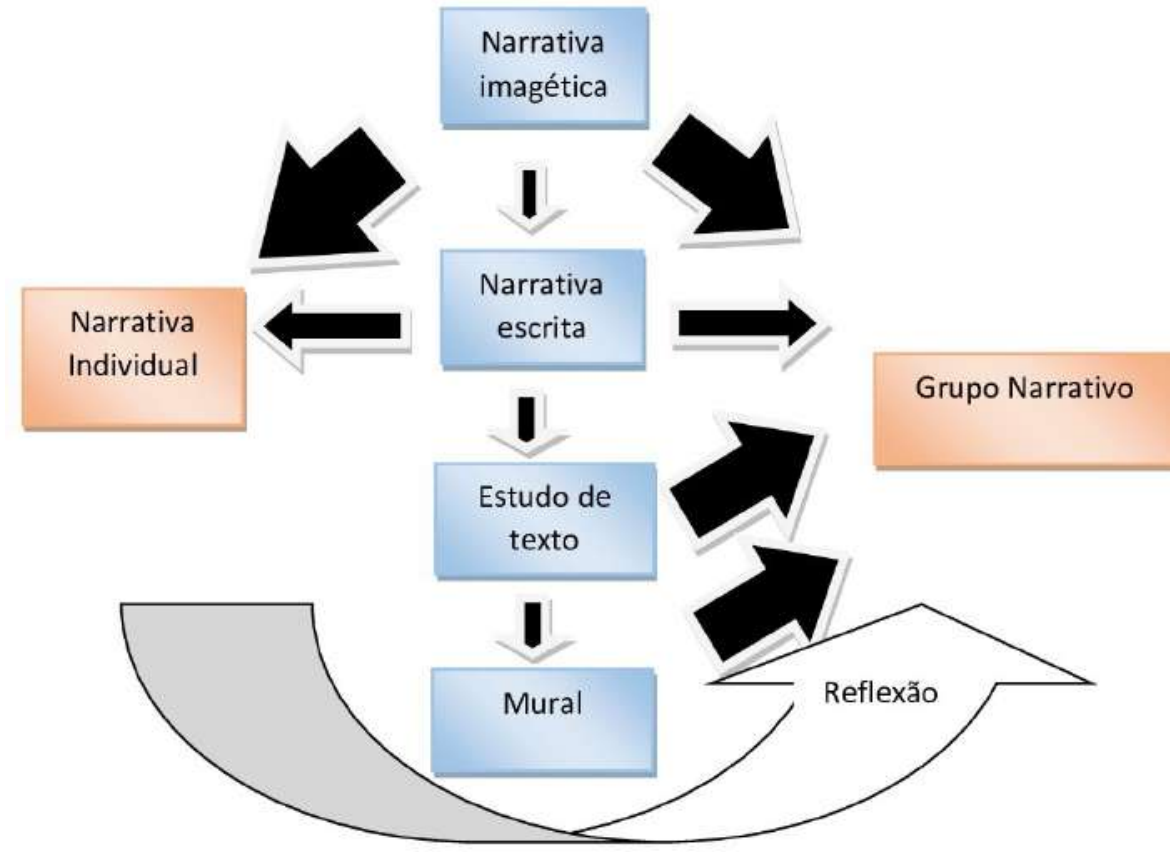

Fonte: Pesquisadoras, 2019.

Num primeiro momento, e de modo objetivo, reunimos e conduzimos o grupo a produzirem, individualmente, uma narrativa imagética (desenho) de seus corpos. Após essa produção, os agrupamos e solicitamos que procedessem a uma produção imagética coletiva do corpo do/a estagiário/ a. O mesmo procedimento foi realizado para a produção escrita (de modo individual e coletivo). A escolha dos procedimentos está relacionada ao desejo de construção coletiva de saberes, conhecimento de si e a observação e escuta atenta um/a do/a outro/a, das suas experiências, vivências, recordações e memórias de corpo.

Assim, o trabalho individual e em grupos narrativos visionou o processo reflexivo e formativo para o trabalho com o tema corpo humano. Para isso, os participantes puderam utilizar tanto material escolar em geral (papel, lápis, coleção, tesoura, cola, etc.), quanto o computador. A produção foi disparada pela proposta de apresentação do corpo do/a estagiário/a, sua identidade, problematizando os marcadores biológicos (fenótipos ${ }^{7}$ ), so-

\footnotetext{
${ }^{7}$ Refere-se as características visíveis que podem ser modificadas.
} 
ciais e culturais atribuídos e percebidos por eles. Esse momento foi nomeado de Estagiário/a, que corpo é esse? A tessitura do desenho apresentou uma infinidade de possibilidades que retratam o que os/as participantes, durante sua formação e vida, apresentam e experimentam como corpo.

Com a narrativa imagética do corpo, buscamos a problematização das concepções de corpo, dos marcadores biológicos, culturais e sociais apresentados; pelas continuidades e rupturas quanto à noção de corpo, sem desprezar "[...] o questionamento das interações entre o sujeito e o seu contexto de aprendizagem" (JOSSO, 2002, p. 108). Desse modo, a observação atenta das pesquisadoras e a manutenção do distanciamento possibilitaram ao participante expressar-se livremente, através de sua produção imagética.

A observação das imagens produzidas, associadas à apresentação oral por cada um/a de seus/as autores/as, foi determinante para o reconhecimento das várias identidades corporais que emergiram e ajudaram a compreender as subjetividades e as pluralidades de corpos construídos. Portanto, a escuta atenta dos relatos orais vinculados aos desenhos foi elemento crucial para a aproximação com o corpo narrado.

Após a escuta atenta dos relatos, os participantes passaram a discorrer sobre o corpo inicialmente produzido. Nesse momento, buscamos pela escrita narrativa a inserção dos/as participantes na constituição dos seus corpos e a proposição de reflexão deles/as sobre o apresentado. Assim, os/as participantes passaram a descrever o corpo não mais de forma oral, e sim por meio de registro escrito, o que permitiu a atribuição de uma riqueza de detalhes e da preocupação em se fazer entender.

Em tese, a escrita da narrativa tem um efeito formador por si só. Isto porque coloca o ator num campo de reflexão, de tomada de consciência sobre sua existência, de sentidos estabelecidos à formação ao longo da vida, dos conhecimentos adquiridos e das análises e compreensões empreendidas sobre a sua vida, do ponto de vista psicológico, antropológico, sociológico e linguístico que a escrita de si e sobre si exige. (SOUZA, 2006, p.60).

Com esse trabalho, convém entender, através da produção do corpo do/a estagiário/a, quais dispositivos foram acessados e que relação possuem com a formação dos/as participantes. As imagens produzidas (narrativas imagéticas) e as narrativas escritas ajudaram a compreender em que 
medida a formação recebida possibilitou agregar conhecimentos biológicos e culturais, continuidades e rupturas com visões hegemônicas ou não de corpo.

Para o atendimento aos objetivos da pesquisa e visando possibilitar a escuta atenta, momentos reflexivos, troca de informações, aproximação entre pares, o partilhar experiências, facilitar a produção imagética e escrita, a apresentação de valores e concepções de corpo, identificação de continuidades e rupturas na percepção de corpo os partícipes foram agrupados em grupos narrativos, em número de cinco. Dessa forma, cada grupo foi constituído por cinco participantes e a produção da narrativa realizada. A utilização de fichas com as cores vermelho, verde, azul, preto e branco ajudaram a definir os integrantes de cada grupo, descartando a constituição dos grupos por indicação do pesquisador, ou por afinidade entre os participantes, fator importante para o contato com concepções de corpo diversas e possível reorganização de ideias. A escolha pela divisão de grupos com cinco integrantes também vai ao encontro do que recomenda Masetto (2003) para a manutenção da produtividade e participação de todos. Os grupos, por sua vez, foram nomeados como G1, G2, G3, G4, G5.

Do mesmo modo que realizado anteriormente, ocorreu a produção imagética do corpo do/a estagiário/a provido de atributos biológicos, sociais e culturais, sendo a este atribuído um nome e características bem definidas coletivamente. Com a produção coletiva, nesse momento, buscamos pelo diálogo entre os/as participantes, para narração do corpo do estagiário/a que os represente, no pensar/refletir sobre características biológicas, culturais e sociais no contexto do Estágio Supervisionado do curso de Ciências Biológicas da UFPI. Com a produção imagética do corpo concluída coletivamente, inicia-se a escrita narrativa desse corpo.

A narrativa, através do texto escrito, "[...] pode ser um indicador do sistema de valores, das suas representações socioculturais, das suas referências de compreensão" (JOSSO, 2002, p.89). Nesse processo, a formação oportuniza o contato com valores plurais que podem emergir de uma mesma referência ou de referências distintas. Então, a experiência em formação fomentou a potencialidade reflexiva da narrativa, através de processo de fazer emergir concepções de corpo, moldadas e modeladas durante a formação e as experiências de vida de cada um/a. Problematizar as referências, valores e modelamentos representou uma potencialidade de outras experiências e discussões sobre corpo e sobre a articulação 
conhecimento biológico e cultura, tão necessária a compreensão da ideia de corpo humano.

Em outro momento da investigação-formação, que intitulamos Histórias-experiências do corpo do/a estagiário/a, os/as participantes foram convidados a criar histórias que envolvessem mais de um dos/as personagens (corpos estagiários/as que foram desenhados), disponibilizando palavras que fazem parte da linguagem biológica, social e cultural. Após a construção das narrativas, a escuta reaparece como ferramenta para socialização da produção. Fomos levantando questões referentes ao processo formativo dos/as alunos/as. O objetivo desse momento constituiu-se como possibilidade de fazer emergir a articulação conhecimento biológico e cultura, problematizando os marcadores biológicos, culturais e sociais na produção do corpo do/a estagiário/a. A criatividade para realização do proposto foi essencial, ajudou a agrupar informações, percepções e vivências que, rememoradas, contribuíram para compor o texto com traços da subjetividade dos/as participantes.

A utilização de palavras para produção do texto, sem que os/as participantes pudessem escolhê-las livremente provocou uma tensão no grupo, que foi imediatamente desfeita por meio de um diálogo. O contar histórias, a reflexão sobre fatos e a comparação de proposições/soluções por eles/as mesmos/as apontadas foi importante para a produção e a eliminação da tensão instalada. As palavras listadas para a realização da atividade foram escolhidas pelas próprias pesquisadoras, que buscaram demarcar o biológico, social e cultural sem desprender-se do espaço de formação. Essa escolha foi intencional, para provocar o entrelaçamento entre conhecimento biológico e cultural. A escuta atenta de trechos de conversas entre os/as estudantes também foi decisivo para a escolha das palavras, já que a relação das mesmas com fatos reais e cotidianos também é parte do entrelaçamento desejado. Assim, aos poucos fomos construindo um repertório de palavras a serem utilizadas na atividade. Palavras conhecidas pelos estagiários/as no espaço universitário e que, de alguma forma, podem estar relacionadas ao estudo do corpo em suas diversas concepções e permitiram a articulação. Algumas delas: gravidez, escola, tetraplégico, evolução, facebook, professor, selfie, congresso, microscópio, internet, anabolizante, piercing, dentre outras.

A leitura das histórias narradas com a utilização das palavras sorteadas (03), nesse momento, surgiu como elemento que despertou a curiosidade dos/as estagiários/as. Na busca pelas relações construídas entre os/as 
personagens criados e as palavras sorteadas fomos reconhecendo uma trama que conduzia a reflexão sobre aspectos que fazem parte do contexto formativo e que podem ser inseridos no processo do ensino de Ciências e Biologia na Educação Básica, de modo a superar uma única visão do corpo e a movimentar a articulação conhecimento biológico e cultural.

Como procedimento metodológico, também foi adotado o estudo coletivo de textos que versam sobre a articulação conhecimento biológico e cultural no ensino de Ciências e Biologia, especificadamente ao tratar do tema corpo no espaço escolar e curricular (Quadro 1). 0 estudo dos textos possibilitou o contato com a produção da área à medida que oferece subsídios para a compreensão da necessária ruptura com a visão unívoca de corpo, aquela apresentada pela biomedicina, desarticulada de dimensões históricas e sociais. Dessa forma, esse momento da pesquisa foi intitulado: "Na formação, o ensino do corpo".

Quadro 1: Textos selecionados para estudo coletivo do tema "corpo humano"

\begin{tabular}{|l|c|}
\hline Texto base & Grupo \\
\hline $\begin{array}{l}\text { SOUZA, N. G. S. Que corpo a escola produz? In: RIBEIRO, P. R. C. } \\
\text { (Org.) Corpos, gêneros e sexualidades: questões possíveis para o } \\
\text { currículo escolar. 3. ed. Rio Grande: Editora da FURG, 2013. }\end{array}$ & G1 \\
\hline $\begin{array}{l}\text { SANTIN, S. O espaço do corpo nas pedagogias escolares. In: Corpo, } \\
\text { Gênero, sexualidade: problematizando práticas educativas e cultu- } \\
\text { rais. Rio Grande: FURG, 2006. }\end{array}$ & G2 \\
\hline $\begin{array}{l}\text { QUADRADO, R. P., BARROS, S. da C. de. Corpos, gêneros e sexualida- } \\
\text { des: tensões e desafios para o currículo escolar. Educação para a }\end{array}$ & G3 \\
Sexualidade. 2014. V. 23. (Coleção Cadernos Pedagógicos da EaD). & \\
\hline $\begin{array}{l}\text { SANTOS, L. H. S. dos. O corpo que pulsa na escola e fora dela. In: Se- } \\
\text { minário Corpo, Gênero e Sexualidade: discutindo práticas educati- } \\
\text { vas, 1. 2007, Rio Grande. Anais. Rio Grande: FURG, 2007. p. 80-92. }\end{array}$ & G4 \\
\hline $\begin{array}{l}\text { QUADRADO, R, P. Corpos Híbridos: problematizando as representa- } \\
\text { ções de corpos no currículo escolar. In: RIBEIRO, P. R. C. (Org.). Cor- } \\
\text { pos, gêneros e sexualidades: questões possíveis para o currículo es- } \\
\text { colar. 3. ed. Rio Grande: Editora da FURG, 2013. }\end{array}$ & G5 \\
\hline
\end{tabular}

Fonte: Dados da pesquisa, 2019.

Assim, o estudo coletivo do texto, com sua posterior apresentação pelos grupos de trabalho, oportunizaram o contato com a literatura ainda desconhecida pelos participantes e a problematização de questões antes 
desconsideradas ou despercebidas como úteis para as discussões referentes à temática corpo humano, como: obesidade, racismo, o corpo na velhice, aborto, identidade de gênero, identidade sexual, homofobia, feminicídio, o corpo apresentado na mídia, bulimia e anorexia, abuso sexual, depressão, suicídio. Questões que passaram a ser percebidas pelos os/as participantes da pesquisa como necessárias ao currículo e que, portanto, deveriam ser contemplados no livro didático. A sugestão foi a de que esses temas estejam agregados a conteúdos de Ciências e Biologia, a fim de não passarem despercebidos pela escola. O fato é que, com a produção dos corpos e posterior contato com a literatura selecionada, ficou evidente a compreensão de que ao corpo biológico são agregados marcadores culturais e sociais, que devem ser valorizados e respeitados em suas constituições. Desse modo, problematizar as questões postas pela cultura hegemônica que classifica, rótula, seleciona, aprisiona e disciplina os corpos é ação docente que deve ser valorizada nos cursos de formação de professores, com vistas à redução das desigualdades sociais oportunizadas pela ausência de reflexão sobre os corpos e sua constituição.

Como a experiência leva a perspectivar novas experiências, os/as participantes foram convidados/as a construírem um mural com o material produzido durante os encontros. Assim, o mural: Que corpo é esse? foi planejado e construído em um espaço da UFPI, para ser apreciado pelos ufipianos e por todos aqueles que interessados tivessem pela temática.

A metodologia utilizada foi suporte para a produção das fontes que dialogam num processo de completude e levam em consideração a diversidade de concepções de corpo constituídas em processos de formação e modos de articulação entre conhecimento biológico e cultura. A narrativa foi, sem dúvida, alternativa potente para compreensão da complexidade do corpo, da articulação conhecimento biológico e cultura, e o Estágio como espaço de interformação, experienciação.

Para a análise interpretativa das fontes (narrativa imagética, oral e escrita) foram pensados três tempos de leitura, assim como Souza (2006), considerando diferentemente o tempo de observar, narrar e refletir sobre o corpo do/a estagiário/a e a articulação conhecimento biológico e cultura. Assim, ficou organizado: Tempo I - leitura individual e cruzada ${ }^{8}$; Tempo II leitura das categorias de análise; Tempo III - leitura interpretativa-compreensiva das fontes. Os tempos aqui apresentados não impossibilitaram o

\footnotetext{
${ }^{8}$ Leitura que possibilita identificar aspectos globais e particularidades através da observância comparativa de dados.
} 
acesso às informações presentes nas fontes em momentos considerados necessários a releituras ou mesmo a reorganização das interpretações. 0 acesso ilimitado às produções contribuiu para o desvelar dos corpos produzidos individualmente e coletivamente, como possíveis contribuições da narrativa no processo formativo, e da articulação conhecimento biológico e cultura. Dessa forma, a dialogicidade entre os tempos foi uma constante.

As análises referentes à metodologia utilizada apontam pela satisfação dos participantes quanto à produção das narrativas e satisfação em agregar à sua formação conhecimentos outrora desconsiderados. Na ação coletiva reconhecer o outro e em si a diferença que na sua plenitude não os torna diferentes, mas singulares, enquanto sujeitos que possuem histórias de vida diversas em contextos plurais.

Desse processo de formação, onde futuros professores/as participam ativamente e passam a compreender as relações, as particularidades, a cultura, a diferença, valoriza-se o humano, a ética, a democracia, reconhecendo os seres humanos como cidadãos de direito, as experiências formativas são portas para o processo de reflexão-ação. (NÓVOA, 1992).

\section{Considerações Finais}

A tratativa da temática corpo humano, essencial no espaço escolar por sua dimensão biológica e sociocultural, às vezes limita-se à aprendizagem de conceitos da biomedicina, vinculado aos interesses da cultura hegemônica, excluindo do seu discurso o processo histórico de constituição dos corpos e os contextos de sua produção. Assim, as marcas corporais, o gênero, a etnia, os adereços que compõem os corpos são descartados, dando margem à compreensão universal do corpo em detrimento às suas singularidades.

No espaço escolar, pensar o trabalho com a temática corpo requer a problematização de questões constituídas como "normais". Dessa forma, os procedimentos metodológicos adotados para a tratativa do corpo devem possibilitar aos sujeitos aprendentes a compreensão de conceitos a partir da imersão no conhecimento de si e do outro enquanto sujeitos constituídos biológica e culturalmente em uma dada sociedade, em dada época histórica. 
Experienciar a narrativa do corpo no contexto do estágio supervisionado apresenta-se como atividade formativa à medida que possibilita conhecer os marcadores biológicos e culturais que constituem os sujeitos, identificar as concepções de corpo que estão arraigadas nos espaços institucionais de formação e as rupturas com tais concepções via reflexão sobre as diversas formar de ser e estar no mundo. Na metodologia de trabalho apresentada, há uma possibilidade de quebra de paradigmas e ampliação de horizontes no que se refere a compreensão do corpo biossociocultural.

\section{Referências}

ABRAHÃO, M. H. M. B. Pesquisa (auto)biográfica - tempo, memória e narrativas. In: ABRAHÃO, M. H. M. B. (Org.). A aventura (auto)biográfica: teoria e empiria. Porto Alegre: EDIPUCRS, 2004.

BENJAMIN, W. Magia e técnica, arte e política: ensaios sobre literatura e história da cultura. São Paulo: Editora Brasiliense, 1996.

BOLÍVAR, A. et al. La investigación biográfico-narrativa em educación: enfoque e metodologia. Madrid: La Muralla, 2001.

CLANDININ, D. J; CONNELLY, F.M. Experiência e História em Pesquisa Qualitativa. 2 ed. Uberlândia: EDUFU, 2015. https://doi.org/10.14393/EDUFU978-85-7078-279-3

FERRAROTTI, F. Sobre a autonomia do método biográfico. In: NÓVOA, A.; FINGER, M. (Org.). $O$ método (auto)biográfico e a formação. Lisboa: Ministério da Saúde, 1988.

GALVÃO, C. Narrativas em Educação. In: Ciências \& Educação, São Paulo: v. 11, n.2, p. 327-345, 2005. https://doi.org/10.1590/S151673132005000200013

JOSSO, M. C. Experiências de vida e formação. Lisboa: EDUCA, 2002. 
JOSSO, M. C. Notas sobre a experiência e o saber de experiência. Revista Brasileira de Educação (online). Rio de Janeiro: 2002, n. 19, p. 20-28. Disponível em: http://www.scielo.br/scielo. Acesso em: 16 de abril.

LARROSA, J. Tecnologias do eu e educação. In: SILVA, T. T. (Org.). O sujeito da educação: estudos foucaultianos. Petrópolis: Vozes, 1994. p. 35-85.

MASETTO, M. T. Competência pedagógica do professor universitário. São Paulo: Summus, 2003.

MOITA, M. C. Percursos de formação e de transformação. In: NÓVOA, A. (Org.). Vidas de professores. Porto: Porto Editora, 1995.

NÓVOA, A. (Org.). Os professores e sua formação. Lisboa: Dom Quixote, 1992.

PÉREZ GÓMEZ, A. O pensamento prático do professor: a formação do professor como profissional reflexivo. In: NÓVOA, A. (Org.). Os professores e a sua formação. Lisboa: Dom Quixote, 1992. p.93-114.

QUADRADO, R, P. Corpos Híbridos: problematizando as representações de corpos no currículo escolar. In: RIBEIRO, P. R. C. (Org.). Corpos, gêneros e sexualidades: questões possíveis para o currículo escolar. 3. ed. Rio Grande: Editora da FURG, 2013. (Caderno Pedagógico Anos Iniciais).

QUADRADO, R. P. Corpos, gêneros e sexualidades: tensões e desafios para o currículo escolar. Educação para a Sexualidade. Rio Grande do Sul: 2014. V. 23. (Coleção Cadernos Pedagógicos da EaD).

SANTIN, S. O espaço do corpo nas pedagogias escolares. In: Corpo, Gênero, sexualidade: problematizando práticas educativas e culturais. Rio Grande: Editora da FURG, 2006.

SANTOS, Luís. H. S. dos. O corpo que pulsa na escola e fora dela. In: Seminário Corpo, Gênero e Sexualidade: discutindo práticas educativas, 1, 2007, Rio Grande. Anais... Rio Grande: FURG, 2007. p. 80-92. 
SOUZA, E. C. de. O conhecimento de si: estágio e narrativas de formação de professores. Rio de Janeiro: DP\&A; Salvador, BA: UNEB, 2006.

SOUZA, N. G. S. Que corpo a escola produz? In: RIBEIRO, P. R. C. (Org.)

Corpos, gêneros e sexualidades: questões possíveis para o currículo escolar.3. ed. Rio Grande: Editora da FURG, 2013b. Caderno Pedagógico Anos Iniciais. 